\title{
MATERNAL AND FOETAL OUTCOMES IN PREGNANCY WITH ISOLATED OLIGOHYDRAMNIOS IN THIRD TRIMESTER
}

\author{
Alpana Singh ${ }^{1}$, Y. Ramadevi ${ }^{2}$ \\ ${ }^{1}$ Associate Professor, Department of Obstetrics and Gynaecology, Malla Reddy Institute of Medical Sciences, Hyderabad. \\ ${ }^{2}$ Senior Resident, Department of Obstetrics and Gynaecology, Malla Reddy Institute of Medical Sciences, Hyderabad.
}

\begin{tabular}{l}
\hline ABSTRACT \\
\hline BACKGROUND \\
One of the most common complications of pregnancy is Oligohydramnios. Often due to impaired placental function, seen most \\
commonly in the third trimester of pregnancy, it has been associated with an increased risk of caesarean delivery for foetal distress. \\
Newborns are at increased risk of low Apgar score at birth and meconium aspiration syndrome. Early detection of oligohydramnios \\
and its management may help in reduction of perinatal morbidity and mortality. The objective of study was to study the foetal and \\
maternal outcome in pregnancy with isolated oligohydramnios in third trimester.
\end{tabular}

\section{MATERIAL AND METHODS}

This study was conducted on 100 patients in a tertiary care hospital from July 2015 to June 2016. Pregnant patients with oligohydramnios in third trimester were selected as per inclusion and exclusion criteria. Detailed history taking, demographic profile, clinical, laboratory and sonographic investigations were done. Patients were managed and followed; maternal and foetal outcomes were noted.

\section{RESULT}

In our study, mean maternal age was $23.02 \pm 3.3 \mathrm{yrs}$. and BMI was $21.18 \pm 2.4$. Incidence of oligohydramnios was frequently observed in primigravida than multigravida ( $61 \%$ vs. $39 \%$ ). Overall incidence of preterm delivery was $31 \%$, IUGR was $13 \%$ and caesarean section was $48 \%$. Incidence of low birth weight was 33\% in our study. $15 \%$ new-borns had Apgar score $<7$ at 5 min. Total $15 \%$ new-borns required NICU care, $3 \%$ needed ventilatory support. Neonatal mortality was 1\%.

\section{CONCLUSION}

Oligohydramnios (i.e. decrease in amniotic fluid volume) is associated with increased risk of intrauterine growth restriction, meconium aspiration syndrome, severe birth asphyxia and low Apgar scores. Intensive foetal surveillance (Non-stress test \& foetal Doppler), proper antepartum and intrapartum care are vital in the management of oligohydramnios. Diagnosis, surveillance and timely intervention decrease perinatal morbidity and mortality and thereby ensure a favourable foetal and maternal outcome.

\section{KEYWORDS}

Oligohydramnios, Amniotic Fluid Index (AFI), Intrauterine Growth Restriction (IUGR), Foetal Distress, Non-Stress Test (NST).

HOW TO CITE THIS ARTICLE: Singh A, Ramadevi Y. Maternal and foetal outcomes in pregnancy with isolated oligohydramnios in third trimester. J. Evolution Med. Dent. Sci. 2016;5(78):5775-5777, DOI: 10.14260/jemds/2016/1303

\section{INTRODUCTION}

Developing foetus in the uterus is encompassed in a membrane lined fluid - amniotic fluid. The amniotic fluid serves several roles during pregnancy. It offers a physical space for the foetal skeleton to shape normally, promotes normal foetal lung development, and cushions the foetus and umbilical cord from compressive forces. Normally, amniotic fluid volume reaches $1 \mathrm{~L}$ by 36 weeks and decreases thereafter to less than $200 \mathrm{~mL}$ at 42 weeks.[1] Diminished amniotic fluid is termed as oligohydramnios.

A gamut of sonographic methods have been used in the past to measure the amount of amniotic fluid. Phelan and

Financial or Other, Competing Interest: None.

Submission 23-08-2016, Peer Review 17-09-2016,

Acceptance 22-09-2016, Published 27-09-2016.

Corresponding Author:

Dr. Alpana Singh,

Associate Professor,

Department of Obstetrics and Gynaecology,

Malla Reddy Institute of Medical Sciences,

Suraram, Hyderabad, Telangana.

E-mail: dralpanasingh21@gmail.com

DOI: $10.14260 /$ jemds/2016/1303

\section{(c) $($ () $\ominus$}

colleagues (1987) described quantification using the amniotic fluid index - AFI.[2] This is calculated by adding the vertical depths of the largest pocket in each of the four equal uterine quadrants. Several factors may modulate the AFI, for example high altitude, fluid restriction and/or dehydration may lower the AFI. Reduction in renal artery end-diastolic velocity is an important factor causing low AFI. An AFI of 8 to $20 \mathrm{~cm}$ is considered normal. Oligohydramnios is defined as an AFI of 5 $\mathrm{cm}$ or less. AFI between 5 and $8 \mathrm{~cm}$ is termed as borderline oligohydramnios. Oligohydramnios is more frequently diagnosed these days due to large scale use of ultrasonography. It affects $2.4 \%$ of pregnancies between 36 40 weeks ${ }^{[3,4]}$ and $12 \%$ of pregnancies at 41 weeks or later. ${ }^{[5]}$ In general, oligohydramnios developing early in pregnancy is less common, frequently associated with congenital anomalies and has a poor prognosis. Oligohydramnios is more common in third trimester, often due to impaired placental function and has been associated with an increased risk of caesarean delivery for foetal distress, as well as low Apgar score, meconium aspiration syndrome and perinatal mortality and morbidity. ${ }^{[5,6]}$ Maternal morbidity increases due to increased rate of induction of labour and operative delivery. Early detection of oligohydramnios and management may help in reducing perinatal morbidity and mortality. 


\section{MATERIAL AND METHODS}

This was a prospective study conducted on 100 pregnant patients in a tertiary care hospital from July 2015 to June 2016. Antenatal patients with amniotic fluid index $<8 \mathrm{~cm}$ in third trimester were selected from obstetric OPD. After detailed history and clinical examination, necessary investigations were done. Patients with isolated oligohydramnios in otherwise normal pregnancy were included in the study. Patients with premature rupture of membrane, multiple pregnancies, post-caesarean pregnancy and medical complications of pregnancy were excluded from study.

Patients were followed at weekly intervals to confirm foetal well-being and pick up any issue that needs to be addressed. All findings and data were meticulously noted and maintained. All the patients with term pregnancy were admitted and decision for termination was taken. Patients with borderline oligohydramnios (5-8 cm AFI) were managed on outpatient basis with daily foetal movement count (DFMC), weekly foetal Doppler study and modified biophysical profile. Patients with severe oligohydramnios $(\leq 5 \mathrm{~cm}$ AFI) were admitted in the hospital and were managed with rest in left lateral position, nutritional supplementation and hydration therapy. Foetal surveillance was done with DFMC, Doppler study, NST and modified biophysical profile. Tests were repeated weekly or more frequently as and when necessary. Two doses of Betamethasone injection $12 \mathrm{mg}$ intramuscular was given 24 hours apart to accelerate foetal lung maturity. Decision of delivery was taken in case of term pregnancy and for abnormality detected on foetal surveillance. Pregnancy was terminated either by induction of labour or by caesarean section. Maternal and foetal outcomes were noted.

\section{RESULTS}

In our study, mean maternal age was $23.02 \pm 3.3$ yrs. and BMI was $21.18 \pm 2.4$. Incidence of oligohydramnios was frequently observed in primigravida than multigravida (61\% vs. $39 \%$ ). Out of 100 cases, 23 cases (23\%) had severe oligohydramnios while rest $(77 \%)$ had borderline oligohydramnios. Oligohydramnios was diagnosed more often after 34 weeks of gestation (74\%). As the outcomes differ before and after 34 weeks of gestation, for the sake of analysis, patients were divided into two groups depending on gestation age at diagnosis - Group A: $<34$ weeks $(n=26)$, Group B: $\geq 34$ weeks $(n=74)$. Pregnancy outcomes of two groups are shown in table 1.

\begin{tabular}{|c|c|c|c|c|c|c|c|c|c|}
\hline \multirow{2}{*}{$\begin{array}{l}\text { Gestation Age } \\
\text { at Diagnosis }\end{array}$} & \multirow{2}{*}{$\begin{array}{c}\text { Severity of } \\
\text { Oligohydramnios }\end{array}$} & \multirow[t]{2}{*}{ IUGR } & \multirow{2}{*}{$\begin{array}{c}\text { Abnormal } \\
\text { Doppler or NST }\end{array}$} & \multicolumn{3}{|c|}{$\begin{array}{l}\text { Preterm Delivery } \\
\text { (<37 wks.) }\end{array}$} & \multicolumn{3}{|c|}{$\begin{array}{l}\text { Term Delivery } \\
\text { (>37 wks.) }\end{array}$} \\
\hline & & & & Total & Vaginal & LSCS & Total & Vaginal & LSCS \\
\hline \multirow{2}{*}{$\begin{array}{l}\text { Group } A<34 \\
\text { Weeks } N=26\end{array}$} & Severe $\mathrm{N}=3$ & 2 & 3 & 3 & 0 & 3 & 0 & 0 & 0 \\
\hline & Borderline $\mathrm{N}=23$ & 3 & 9 & 7 & 4 & 3 & 16 & 8 & 8 \\
\hline \multirow{2}{*}{$\begin{array}{l}\text { Group B >34 } \\
\text { Weeks N=74 }\end{array}$} & Severe N=20 & 6 & 7 & 16 & 7 & 9 & 4 & 3 & 1 \\
\hline & Borderline $\mathrm{N}=54$ & 2 & 7 & 5 & 3 & 2 & 49 & 27 & 22 \\
\hline Total & & 13 & 26 & 31 & 14 & 17 & 69 & 38 & 31 \\
\hline \multicolumn{10}{|c|}{ Vaginal Deliveries $=52, \mathrm{LSCS}=48$} \\
\hline
\end{tabular}

In group A, 3 had severe oligohydramnios at diagnosis and of them 2 had intrauterine growth restriction (IUGR). All required emergency caesarean section for foetal distress and had low Apgar at birth. One baby survived while 2 died in the neonatal period. The rest in group A (23 patients), who had borderline oligohydramnios were managed on OPD basis. During followup, 5 developed severe oligohydramnios, 3 developed IUGR and 9 had abnormal Doppler/NST changes. 7 patients ended up with a preterm delivery, while 16 patients terminated at term. 12 patients delivered vaginally and caesarean section was performed on 11 patients.

In group B, 20 patients had severe oligohydramnios at diagnosis. Out of them, 6 developed IUGR and 7 developed abnormal NST and/or Doppler study. 16 cases had to be delivered before term and 4 cases delivered at term. 10 cases delivered vaginally and the rest required caesarean section. Rest 54 cases in group B were borderline oligohydramnios at diagnosis. During follow-up, 11 cases progressed to severe oligohydramnios, 2 cases developed IUGR and 7 cases developed abnormal Doppler and/or NST changes. Out of 54 cases, 49 cases delivered at term and rest had to be delivered before term. 30 cases delivered vaginally while caesarean section was performed in the rest 12 cases.

In this study of pregnant women with oligohydramnios, overall incidence of preterm delivery was $31 \%$, IUGR was $13 \%$ and caesarean section was $48 \%$.
Table 2 shows the different indications of caesarean section in our study. The most common indication was foetal distress $(62.5 \%)$.

\begin{tabular}{|c|c|c|}
\hline Indication & No. & Percentage \\
\hline Foetal Distress & 30 & $(62.5 \%)$ \\
\hline Failed Induction & 8 & $(16.6 \%)$ \\
\hline Cephalopelvic Disproportion & 6 & $(12.5 \%)$ \\
\hline Breech & 3 & $(6.25 \%)$ \\
\hline Transverse Lie & 1 & $(2 \%)$ \\
\hline \multicolumn{3}{|c|}{ Table 2: Indications of Caesarean Section } \\
\hline
\end{tabular}

Foetal outcomes are shown in table 3. Incidence of low birth weight was 33\% in our study. $15 \%$ newborns had Apgar score $<7$ at 5 min. Total 15\% newborns required NICU care, 3 out of them needed ventilatory support. One preterm baby on ventilator died 24 hours after birth.

\begin{tabular}{|c|c|c|}
\hline Foetal Outcomes & Number & Percentage \\
\hline Gestation Age Term & 31 & $31 \%$ \\
\hline Preterm & 69 & $69 \%$ \\
\hline Apgar score at 5 min. $\geq 7$ & 85 & $85 \%$ \\
\hline$<7$ & 15 & $15 \%$ \\
\hline Birth Weight $\geq 2.5 \mathrm{~kg}$. & 67 & $67 \%$ \\
\hline$<2.5 \mathrm{~kg}$. & 33 & $33 \%$ \\
\hline NICU Admission & 15 & $15 \%$ \\
\hline Ventilatory Support & 3 & $3 \%$ \\
\hline Neonatal Death & 1 & $1 \%$ \\
\hline \multicolumn{2}{|c|}{ Table 3: Foetal Outcomes in Patients } \\
with Oligohydramnios
\end{tabular}




\section{DISCUSSION}

Oligohydramnios or decrease in amniotic fluid volume has been correlated with increased risk of intrauterine growth restriction, meconium aspiration syndrome, severe birth asphyxia, low Apgar scores and congenital abnormalities. Oligohydramnios may be considered as an indicator of impaired placental function, foetal compromise and requires intensive foetal surveillance.

In our study, incidence of oligohydramnios is more in primigravida (61\%) than in multigravida. A similar study done by Donald D et al in 2000[7] and Hindumathi et al in 2015[8] showed $60 \%$ and $59 \%$ incidence of oligohydramnios in primigravida, respectively.

Diagnosis of oligohydramnios is more common in the third trimester. In our study, 74\% cases were diagnosed after 34 weeks of pregnancy. Similar study done by Jun Zhang et al in 2004 found a mean gestation age of $38.1 \pm 3.3$ weeks at diagnosis. ${ }^{[9]}$

Our study showed $31 \%$ incidence of preterm delivery in oligohydramnios cases, due to diagnosis of severe oligohydramnios before term and abnormal Doppler and unfavourable NST changes. Intrauterine growth restriction was observed in $13 \%$ cases due to early diagnosis of oligohydramnios indicating uteroplacental insufficiency.

In our study, $52 \%$ cases delivered vaginally while the rest required a caesarean section, commonest indication being foetal distress (62.5\%) which is comparable to a study conducted by Sowmya K et al in 2014.[10] They compared the pregnancy outcomes of patients with oligohydramnios with those having normal AFI and found the caesarean rate of $68 \%$ in oligohydramnios patient while $28 \%$ in normal liquor group. Foetal distress was the indication of caesarean in $78 \%$ cases.

The incidence of low birth weight (LBW) in our study is $33 \%$. Study by Sowmya K et al had shown $48 \%$ incidence of low birth weight. $15 \%$ of our babies had Apgar score $<7$ and required NICU admission. Similar incidence of $15 \%$ was found by Hindumathi $\mathrm{M}$ et al.[8] Casey et al[7] in 2000 conducted a study on pregnancy outcomes after antepartum diagnosis of oligohydramnios at or beyond 34 weeks' gestation and reported an NICU admission rate of $7 \%$ in patients with oligohydramnios. $3 \%$ of our babies required ventilator support, and 1 died on second neonatal day. Golen et al in 1994[11] and Wolff et al in 1994[12] reported 6.3\% and 7.2\% neonatal mortality respectively.

\section{CONCLUSION}

Nowadays oligohydramnios is more frequently diagnosed due to routine use of ultrasonography and is associated with increased perinatal mortality and morbidity. Management depends on the gestation age at diagnosis and its severity. It demands intensive foetal surveillance and proper antepartum and intrapartum care. Timely intervention is required to prevent perinatal morbidity and mortality.

\section{REFERENCES}

1. Hoffmann B. Disorders of amniotic fluid volume. 23rd ed. In: Williams obstetrics. McGraw-Hill Professional 2011.

2. Phelan JP, Ahn MO, Smith CV, et al. Amniotic fluid measurements during pregnancy. J Reprod Med 1987; 32(8):601-4.

3. Phelan JP, Smith CV, Broussard P, et al. Amniotic fluid volume assessment with four quadrant technique at 3642 weeks gestation. J Reprod Med 1987;32(7):540-2.

4. Phelan JP, Platt LD, Yeh S, et al. The role of ultrasound assessment of amniotic fluid volume in the management of the postdate pregnancy. Am J Obstet Gynecol 1985; 151(3):304-8.

5. Michael Y, Divon MD, Ariel D, et al. Longitudinal measurement of amniotic fluid index in post term pregnancies and its association with fetal outcome. Am J Obstet Gynecol 1995;172(1 Pt 1):142-6.

6. Chauhan SP, Sanderson M, Hendrix NW, et al. Perinatal outcome and amniotic fluid index in the antepartum and intrapartum periods: a meta-analysis. Am J Obstet Gynecol 1999;181(6):1473-8.

7. Casey BM, McIntire DD, Bloom SL, et al. Pregnancy outcomes after antepartum diagnosis of oligohydramnios at or beyond 34 weeks gestation. Am J Obstet Gynecol 2000;182(4):909-12.

8. Hindumathi M, Karthiki J, Ramamani, et al. A prospective study of maternal and fetal outcome in oligohydramnios in rural area. International J of Recent advances in multidisciplinary research 2015;11:0985-8.

9. Zhang J, Troendle J, Meikle $\mathrm{S}$, et al. Isolated oligohydramnios is not associated with adverse perinatal outcomes. Int J Gynaecol Obstet 2004;111(3):220-5.

10. Sowmya K, Betty V, Borkar UY, et al. Effect of isolated oligohydramnios in otherwise normal term pregnancy. International Journal of Biomedical Research 2014; 5(2):98-101.

11. Golan A, Lin G, Evron S, et al. Oligohydramnios: maternal complications and fetal outcome in 145 cases. Gynecol Obstet Invest 1994;37(2):91-5.

12. Wolff F, Schaefer R. Oligohydramnios-perinatal complications and diseases in mother and child. Geburtshilfe Frauenheilkd 1994;54(3):139-43. 